\title{
Belowground fungal community diversity, composition and ecological functionality associated with winter wheat in conventional and organic agricultural systems
}

\author{
Sigisfredo Garnica ${ }^{\text {Corresp., } 1}$, Ronja Rosenstein ${ }^{2}$, Max Emil Schön ${ }^{3}$ \\ 1 Instituto de Bioquimica y Microbiologia/ Facultad de Ciencias, Universidad Austral de Chile, 5090000 Valdivia, Isla Teja, Chile \\ 2 Institute of Evolution and Ecology, Plant Evolutionary Ecology, University of Tuebingen, Tuebingen, Germany \\ 3 Department of Cell and Molecular Biology, Science for Life Laboratory, Uppsala University, Uppsala, Sweden \\ Corresponding Author: Sigisfredo Garnica \\ Email address: sigisfredo.garnica@uach.cl
}

Understanding the impacts of agricultural practices on belowground fungal communities is crucial in order to preserve biological diversity in agricultural soils and enhance their role in agroecosystem functioning. Although fungal communities are widely distributed, relatively few studies have correlated agricultural production practices. We investigated the diversity, composition and ecological functionality of fungal communities in roots of winter wheat (Triticum aestivum) growing in conventional and organic farming systems. Direct and nested polymerase chain reaction (PCR) amplifications spanning the internal transcribed spacer (ITS) region of the rDNA from pooled fine root samples were performed with two different sets of fungal specific primers. Fungal identification was carried out through similarity searches against validated reference sequences (RefSeq). The $R$ package 'picante' and FUNGuild were used to analyse fungal community composition and trophic mode, respectively. Either by direct or cloning sequencing, 130 complete ITS sequences were clustered into 39 operational taxonomic units (OTUs) (25 singletons), belonging to the Ascomycota (24), the Basidiomycota (14) and to the Glomeromycota (1). Fungal communities from conventional farming sites are phylogenetically more related than expected by chance. Constrained ordination analysis identified total N, total S and Pcal that had a significant effect on the OTU's abundance and distribution, and a further correlation with the diversity of the co-occurring vegetation could be hypothesised. The functional predictions based on FUNGuild suggested that conventional farming increased the presence of plant pathogenic fungi compared with organic farming. Based on diversity, OTU distribution, nutrition mode and the significant phylogenetic clustering of fungal communities, this study shows that fungal communities differ across sampling sites, depending on agricultural practices. Although it is not fully clear which factors determine the fungal communities, our findings suggest that organic farming systems have a positive 
effect on fungal communities in winter wheat crops. 
1 Belowground fungal community diversity, composition and ecological functionality

2 associated with winter wheat in conventional and organic agricultural systems

3

4

5

6

7

8

9

10

26

27

28

29

30

31

32

33

34

35
Sigisfredo Garnica $^{1}$, Ronja Rosenstein ${ }^{2}$, Max Emil Schön ${ }^{3}$

${ }^{1}$ Instituto de Bioquímica y Microbiología, Facultad de Ciencias, Universidad Austral de Chile, Isla Teja, 5090000 Valdivia, Chile

${ }^{2}$ Institute of Evolution and Ecology, Plant Evolutionary Ecology, University of Tübingen, 72076

Tübingen, Germany

${ }^{3}$ Department of Cell and Molecular Biology, Science for Life Laboratory, Uppsala University, SE-75123 Uppsala, Sweden

Corresponding Author:

Sigisfredo Garnica ${ }^{1}$ 5090000 Valdivia, Isla Teja, Chile

Email address: sigisfredo.garnica@uach.cl 
36 Understanding the impacts of agricultural practices on belowground fungal communities is

37 crucial in order to preserve biological diversity in agricultural soils and enhance their role in 38 agroecosystem functioning. Although fungal communities are widely distributed, relatively few 39 studies have correlated agricultural production practices. We investigated the diversity, 40 composition and ecological functionality of fungal communities in roots of winter wheat 41 (Triticum aestivum) growing in conventional and organic farming systems. Direct and nested 42 polymerase chain reaction (PCR) amplifications spanning the internal transcribed spacer (ITS) 43 region of the rDNA from pooled fine root samples were performed with two different sets of 44 fungal specific primers. Fungal identification was carried out through similarity searches against 45 validated reference sequences (RefSeq). The R package 'picante' and FUNGuild were used to 46 analyse fungal community composition and trophic mode, respectively. Either by direct or 47 cloning sequencing, 130 complete ITS sequences were clustered into 39 operational taxonomic 48 units (OTUs) (25 singletons), belonging to the Ascomycota (24), the Basidiomycota (14) and to 49 the Glomeromycota (1). Fungal communities from conventional farming sites are 50 phylogenetically more related than expected by chance. Constrained ordination analysis 51 identified total $\mathrm{N}$, total $\mathrm{S}$ and Pcal that had a significant effect on the OTU's abundance and 52 distribution, and a further correlation with the diversity of the co-occurring vegetation could be 53 hypothesised. The functional predictions based on FUNGuild suggested that conventional 54 farming increased the presence of plant pathogenic fungi compared with organic farming. Based 55 on diversity, OTU distribution, nutrition mode and the significant phylogenetic clustering of 56 fungal communities, this study shows that fungal communities differ across sampling sites, 57 depending on agricultural practices. Although it is not fully clear which factors determine the 
58 fungal communities, our findings suggest that organic farming systems have a positive effect on

59 fungal communities in winter wheat crops.

60

61

62

63

\section{Introduction}

64

65 Crop production has increased over time because of the growing global demand particularly for 66 food, feed and fuel supplies. To meet this demand, diverse agricultural farming systems are 67 being developed in an attempt to contribute to increased crop production yields (Tilman et al. 68 2011). Although there are many different agricultural techniques, these can be generalised, 69 depending on the techniques used, as either conventional or organic (sustainable) systems. 70 Basically, conventional farming uses synthetic chemicals and fertilisers and is designed 71 specifically to generate maximal yields, whereas organic farming aims to produce a number of 72 crops without the use of synthetic chemicals or fertilisers (Gomiero et al. 2011). The effects of 73 such methods on physical and chemical soil properties have been well studied. Although

74 previous studies have demonstrated that crop and soil management practices have a significant 75 impact on soil microorganisms (Seghers et al. 2004; Zarb et al. 2005), we still have little 76 knowledge of how land use may affect the abundance and composition of specific taxonomic 77 groups.

78

79 Some previous studies have found greater soil fungi abundance (e. g. Shannon et al. 2002;

80 Tautges et al. 2016) and higher arbuscular mycorrhizal fungal colonisation (Gryndler et al. 2006;

81 Mäder et al. 2002; Oehl et al. 2004) in organic than in conventionally managed wheat (Triticum 
82 aestivum) production systems. Perhaps the fungal groups of major interest are probably those 83 that live in endophytic association with crop plants. For winter wheat, one of the most important 84 food crop plants worldwide (O'Hanlon et al. 2012), previous studies by Carter et al. (1999), 85 Larran et al. (2007), Riess et al. (2014) and Verbruggen et al. (2014) have examined the effects 86 of agricultural management on the diversity and composition of root fungal endophyte 87 communities. By using a combination of cultural characteristics and subsequent identification by 88 sequencing rDNA, Carter et al. (1999) examined fungal endophytes associated with plant roots. 89 Larran et al. (2007) used classical cultivation and morphology-based methods to identify 90 endophytic fungi isolated from aboveground plant tissues of different cultivars. By using 91 cultivation and sequencing methods, Riess et al. (2014) focused on the detection of endophytic 92 Sebacinales from roots across different agricultural habitats. Verbruggen et al. (2014) found that 93 Sebacinales but not total roots associated fungal communities are affected by land use intensity. 94 In all these studies, fungal molecular operational taxonomic units (OTUs) or species, mainly 95 Ascomycota and some Basidiomycota, were detected to be the most common root-colonising 96 endophytes. So far, some experimental studies for agriculturally relevant crop plants have 97 demonstrated that endophytes can increase tolerance to environmental factors like drought and 98 heat, as reported by Hubbard et al. (2014), or provide resistance against herbivory (Gurulingappa 99 et al. 2010). They have also been shown to be involved in fungal pathogen protection and/or 100 growth promotion in wheat (Rabiey et al. 2015). However, apart from these potential effects on 101 plants, we still have poor knowledge of how agricultural practices may influence these root102 colonising microbial communities in the field. 
104 In this work, we selected five sites each from the two most commonly applied farming systems

105 to examine specifically how belowground fungal communities respond to different agricultural

106 practices using winter wheat as the target plant, which is of great economic importance and is the

107 predominant crop in Germany (Statistisches Bundesamt Wiesbaden 2015). The main proportion

108 of cereal cropland (96\% in 2013) in Germany is based on conventional agriculture; however,

109 between 2003 and 2013, the number of agricultural holdings practicing organic farming

110 increased by 30\% (Statistisches Bundesamt Wiesbaden 2014). We sequenced the internal

111 transcribed spacer (ITS) region of the rDNA directly or after cloning and analysed it to identify

112 and characterise the belowground fungal communities associated with roots of winter wheat

113 from agricultural sites under conventional or organic management. Four specific questions are

114 addressed: (i) What is the diversity of these communities associated with winter wheat associated

115 with these agricultural practices? (ii) What are the patterns in phylogenetic structure

116 characterising such communities? (iii) Do biotic and/or abiotic environmental factors affect the

117 phylogenetic diversity and structure of the communities associated with winter wheat? (iv) What

118 is the ecological function of these fungal communities? In order to cover as much of the fungal

119 diversity as possible, we used two different sets of specific primers to characterise the diversity

120 in the roots. We used this sequence-based approach to characterise the diversity and community

121 composition of these microorganisms across sites under two different agricultural practices and 122 associated with the influence of selected biotic and/or abiotic environmental factors.

123 Materials \& Methods

124

\section{Study sites}

126 During the end of April 2015, winter wheat (Triticum aestivum) plants were sampled from 10 127 different sites located in the surroundings of Tübingen, Baden-Württemberg, Germany (see Fig. 
128 1). We sampled agricultural fields treated under conventional farming management located in

129 Pfrondorf (C1, C2 and C4) and Entringen (C3 and C5) as well as fields under organic farming

130 management located in Unterjesingen (O1, O2, O3, O4 and O5). Within each agricultural field,

131 plants were collected along a diagonal transect. Organic farming sites most commonly featured

132 frequent and diverse co-occurring herbaceous plants. Site O2 was also surrounded by shrubs and

133 site $\mathrm{O} 3$ was located next to a group of ectomycorrhizal (ECM) trees. For the conventional

134 farming sites, sites C2 and C3 had more diverse co-occurring plant species. A complete list of

135 co-inhabiting plants at each collection site is given as supplementary information (Table S1).

136

137 Plant and soil sample collection

138 Plants from a sampling transect, defined as the longest diagonal between two of the corners of 139 each site, were sampled. Along each transect, 10 plots (labelled A to J) were positioned at similar 140 distance intervals, with the two outer plots (A and J) being placed directly in the corners, the 141 distance between plots ranged from $8 \mathrm{~m}$ to $28 \mathrm{~m}$ (Table S1). Within each sampling plot, at least

142 five different plants at the tillering stage were randomly chosen and carefully dug out of the 143 ground with a shovel, retaining as much of the root system as possible and a portion of soil. Plant 144 size ranged from approximately $15 \mathrm{~cm}$ to $30 \mathrm{~cm}$; individuals growing in the corners of the sites 145 were always smaller than those growing in the central area. Sampled plants were stored in plastic 146 bags at $4^{\circ} \mathrm{C}$ until further processing.

148 The root systems of each plant were soaked in tap water to loosen the soil and were then washed 149 extensively under running tap water. Subsequently, the five plants per plot with the highest 150 number of healthy roots were chosen for molecular analysis. The roots were washed carefully 
151 under running purified water, then three fine roots per plant were randomly selected, cut off with

152 a sterile scalpel and forceps, and were placed into a Petri dish filled with double-distilled and

153 sterilised water. Root surface sterilisation was performed via a modified version of the method of

154 Sun et al. (2008), which consisted of rinsing the roots in ethanol (70\%) for 5 min in a Petri dish,

155 then in sodium hypochlorite $(\mathrm{NaOCl} 1 \%)$ for another $5 \mathrm{~min}$ and finally washing them with

156 double-distilled water three times to remove any remaining chemicals. After that procedure, all

15715 root portions from each plot (three root segments from five plants each) were pooled together

158 as one sample, placed into 2-mL Eppendorf tubes and dried at $50^{\circ} \mathrm{C}$ in a Dörrex device for

159 several days. In total, the roots of 500 plants were randomly sampled (representing 100 pooled

160 samples), 250 plants for each of the two different farming methods. Herbarised plants were

161 deposited in the Herbarium Tubingense (TUB) as Nos TUB 021591 to TUB 021628.

162

163 In addition, from each plot, portions of soil adhering to the roots of the sampled plants were 164 removed and stored in paper bags for drying. Two soil samples per site were analysed

165 independently: soil from the two edge plots was mixed and pooled as one sample, whereas the 166 soil from the remaining middle plots was used as a second sample. Measurements of total carbon 167 and nitrogen content as well as organic carbon content, $\mathrm{pH}$ and plant-available phosphorus 168 content were conducted at the Soil Science and Geoecology Laboratory of the University of 169 Tübingen. Additionally, the carbon-to-nitrogen ratio was calculated and the humus content was 170 estimated by multiplying the organic carbon content by 1.72 as described by Ad-hoc 171 Arbeitsgruppe Boden (2005). 


\section{DNA extraction, amplification, cloning and DNA sequencing}

173 Dried fine root pools were homogenised with a mixer mill (MM 300; Retsch GmbH, Haan,

174 Germany) with two steel beads per Eppendorf tube at a frequency of $30 \mathrm{~Hz}$ for $10 \mathrm{~min}$. Total 175 gDNA was extracted with the InnuPREP Plant DNA Kit (Analytik Jena AG, Jena, Germany)

176 following the manufacturer's protocol, except that the amounts of lysis buffer, RNase, protein

177 kinase and binding solution were doubled in order to dissolve the large volume of homogenised 178 root material completely. To detect root-associated fungi, PCRs were performed to amplify the 179 ITS region by following two different approaches: (i) the first approach was used to amplify the 180 ITS region including the 5.8S domain with the fungal-specific primer ITS1F (Gardes \& Bruns 181 1993) and the universal primer ITS4 (White et al. 1990); (ii) in the second approach, the ITS 182 region and the large subunit domain D1/D2 were amplified with the fungal-specific primers 183 NSI1 (Martin \& Rygiewicz 2005) and NL4 (White et al. 1990). PCR products from the second 184 approach (for samples producing negative or weak PCR products) were subsequently used for 185 nested PCRs with the primer combination ITS1F-ITS4. In both cases, MangoTaq ${ }^{\mathrm{TM}}$ DNA Polymerase (Bioline $\mathrm{GmbH}$, Lückenwalde, Germany) was used for amplification and the reactions consisted of a volume of $25 \mu \mathrm{L}$ containing $5 \mu \mathrm{L}$ coloured reaction buffer, $14.5 \mu \mathrm{L}$ double-distilled $\mathrm{H}_{2} \mathrm{O}, 0.75 \mu \mathrm{L} \mathrm{MgCl}_{2}(50 \mathrm{mM}), 1 \mu \mathrm{L}$ dNTPs $(5 \mathrm{mM}), 0.5 \mu \mathrm{L}$ of the forward primer $(25 \mathrm{pmol} / \mu \mathrm{L}), 0.5 \mu \mathrm{L}$ of the reverse primer $(25 \mathrm{pmol} / \mu \mathrm{L}), 0.25 \mu \mathrm{L}$ MangoTaq DNA primers, PCR reactions consisted of half the volume. PCRs were run with the thermo program TOUCH 60 under the following conditions: initial denaturation at $94^{\circ} \mathrm{C}$ for $3 \mathrm{~min} ; 10$ cycles each of denaturation at $94^{\circ} \mathrm{C}$ for $30 \mathrm{~s}$, annealing at $60^{\circ} \mathrm{C}$ for $45 \mathrm{~s}$, with each cycle decreasing by $1^{\circ} \mathrm{C}$, and elongation at $72^{\circ} \mathrm{C}$ for $1 \mathrm{~min} 15 \mathrm{~s}$, followed by 26 cycles each of denaturation at $94^{\circ} \mathrm{C}$ for 30 
$195 \mathrm{~s}$, annealing at $50^{\circ} \mathrm{C}$ for $45 \mathrm{~s}$, elongation at $72^{\circ} \mathrm{C}$ for $1 \mathrm{~min} 15 \mathrm{~s}$ and a final extension phase at

$19672^{\circ} \mathrm{C}$ for $7 \mathrm{~min}$. PCR products were verified by running an agarose gel electrophoresis with $0.7 \%$ 197 agarose and $1 \times$ Tris-Borat-EDTA (TBE) buffer for $15 \mathrm{~min}$ at $143 \mathrm{~V}$. The PCR products were 198 subsequently stained with Midori Green (NIPPON Genetics EUROPE GmbH, Dueren, 199 Germany) for 30 min and visualised under UV illumination.

200

201 Positive PCR products that could not be sequenced directly were cloned into competent 202 Escherichia coli cells with the TOPO TA Cloning® Kit for Sequencing (Invitrogen, Life 203 Technologies GmbH, Darmstadt, Germany). The cloning reaction for one sample contained 0.33 $204 \mu \mathrm{L}$ of a salt solution, $0.33 \mu \mathrm{L}$ double distilled $\mathrm{H}_{2} \mathrm{O}, 0.33 \mu \mathrm{L}$ of $\mathrm{pCR} \AA 4-\mathrm{TOPO}$ vector 205 (Invitrogen) and $1 \mu \mathrm{L}$ of the undiluted PCR product. Samples were incubated at room 206 temperature for $30 \mathrm{~min}$. Afterwards, $19 \mu \mathrm{L}$ of One Shot ${ }^{\circledR}$ TOP10 chemically competent E. coli 207 cells (Invitrogen) was carefully added to the cloning reaction and the mixture subsequently 208 incubated on ice for $30 \mathrm{~min}$. Heat shock was conducted in a water bath at $42^{\circ} \mathrm{C}$ for $30 \mathrm{~s}$, after 209 which the cells were kept on ice for 2 min. Finally, after adding $80 \mu \mathrm{L}$ of Super Optimal broth 210 Catabolite repression (S.O.C.) medium, the mixture was placed into an incubator at $37^{\circ} \mathrm{C}$ and $211200 \mathrm{rpm}$ for 1 hour, then plated onto Lysogeny Broth (LB)-medium including Kanamycin (1 $212 \mathrm{~mL} / \mathrm{L})$. Plates were incubated at $37^{\circ} \mathrm{C}$ overnight. Up to 12 bacterial colonies per sample were 213 picked and directly used for PCRs with the forward and reverse primers M13F/M13R 214 (Invitrogen) and MangoTaq DNA Polymerase in $25-\mu \mathrm{L}$ reactions. Amplification in the thermo 215 program M13 consisted of initial denaturation at $94^{\circ} \mathrm{C}$ for $7 \mathrm{~min}$, followed by 32 cycles each of 216 denaturation at $94^{\circ} \mathrm{C}$ for $20 \mathrm{~s}$, annealing at $55^{\circ} \mathrm{C}$ for $40 \mathrm{~s}$, elongation at $72^{\circ} \mathrm{C}$ for 2 min $40 \mathrm{~s}$ and a 217 final extension at $72^{\circ} \mathrm{C}$ for $7 \mathrm{~min}$. For samples with a large number of positive PCR products, 
218 eight clones were digested enzymatically with Hinfl (New England BioLabs GmbH, Frankfurt 219 am Main, Germany) to detect restriction fragment length polymorphisms. To check for different 220 restriction patterns, gel electrophoresis was run with $1 \%$ agarose and $1 \times$ Tris-EDTA (TE) buffer 221 at $120 \mathrm{~V}$ for $40 \mathrm{~min}$, followed by staining with Midori Green (Nippon Genetics EUROPE $222 \mathrm{GmbH}$ ) for $30 \mathrm{~min}$ and visualisation under UV illumination. All PCR products showing different 223 restriction patterns were sequenced, as well as some with the same pattern.

224

225

Amplified PCR products were cleaned up with diluted (1:20) ExoSAP-IT® (Affymetrix UK Ltd, 226 High Wycombe, UK) following the manufacturer's protocol. Cycle sequencing was performed 227 on $4 \mu \mathrm{L}$ of a 1:6 diluted ABI PRISM BigDye ${ }^{\circledR}$ Terminator v3.1 Cycle Sequencing Kit (Applied Biosystems, Life Technologies GmbH, Darmstadt, Germany) and $1 \mu \mathrm{L}$ of the primers ITS1F229 ITS4 and, if necessary, 5.8SR (Vilgalys \& Hester 1990), ITS2 or ITS1 (White et al. 1990) (12 $\mathrm{pmol} / \mu \mathrm{L})$ for directly sequenced PCR products and the primers M13F-M13R (12 pmol/ $\mu \mathrm{L})$ for 231 cloned PCR products. The thermo program ABI31CYCL was used for amplification under 232 following conditions: initial denaturation at $96^{\circ} \mathrm{C}$ for $1 \mathrm{~min}$, followed by 27 cycles each of 233 denaturation at $96^{\circ} \mathrm{C}$ for $10 \mathrm{~s}$, annealing at $50^{\circ} \mathrm{C}$ for $5 \mathrm{~s}$ and elongation at $60^{\circ} \mathrm{C}$ for $4 \mathrm{~min}$. 234 Afterwards, the cycle sequencing products were precipitated in 75\% isopropanol, washed with $23580 \%$ ethanol and dried in a vacuum centrifuge for approximately $5 \mathrm{~min}$. DNA pellets were 236 dissolved in $15 \mu \mathrm{l} \mathrm{Hi-Di}{ }^{\mathrm{TM}}$ formamide (Applied Biosystems, Life Technologies, Warrington, $237 \mathrm{UK}$ ) for 10 min and sequencing was conducted on an ABI3130xl Genetic Analyzer (Applied 238 Biosystems, Foster City, CA, USA). A list of primers used in this study, including their 239 sequences, is given in the supplementary information (Table S2). 


\section{Sequence editing, chimera checking and BLAST search}

242 Forward and reverse ITS sequences were assembled automatically and edited manually by 243 Sequencher v.4.9 (Gene Codes Corporation, Ann Arbor, MI, USA).

244

245 All sequences were first checked for PCR chimeras with VSEARCH v2.4.3 (Rognes et al. 2016), 246 implementing the UCHIME algorithm (Edgar et al. 2011). All chimeric and 'borderline' 247 chimeric sequences were excluded from further analyses. Non-chimeric ITS sequences with 248 GenBank accession nos. KY430446 to KY430584 were used as queries in a search against the 249 GenBank ITS RefSeq Database (BioProject PRJNA177353, accessed 12 December 2018) with 250 the program MALT (Herbig et al. 2016), using the default parameters. The ITS sequences 251 generated in this study were then annotated with the most specific taxonomic label inferred.

252

253 Fungal diversity estimation

254 Fungal ITS sequences were clustered into OTUs based on a $\geq 97 \%$ similarity threshold with the 255 UCLUST algorithm implemented in VSEARCH (Edgar 2010; Rognes et al. 2016). We estimated 256 the alpha diversity of those samples by calculating Hill numbers in the R package 'vegan' 257 (Oksanen et al. 2016). We also computed the number of OTUs that were shared by the two 258 farming systems and the number of OTUs that were unique to a specific system. A pairwise 259 species distance matrix was computed by first calculating the pairwise sequence distances via the 260 alignment-free approach of spaced-words frequencies (Leimeister et al. 2014). Pairwise 261 sequence distances were subsequently averaged to pairwise species (OTU) distances. 


\section{Phylogenetic community structure}

264 We calculated the standardised effect sizes of the mean phylogenetic distance (MPD, equivalent 265 to - net relatedness index (NRI), Webb 2002) and the mean nearest phylogenetic taxon distance 266 (MNTD, equivalent to - nearest taxon index (NTI)) metrics as implemented in the R package 267 'picante' to assess the composition of fungal samples in conventional vs. organically managed 268 farming sites (Kembel et al. 2010). We compared the MPD and MNTD values for our samples 269 with random samples generated under a null model that shuffled species labels randomly across 270 the complete phylogeny.

271

\section{Differences in environmental factors between farming methods}

273 The differences in measured soil parameters between organic and conventional plots were 274 visualised via non-metric multidimensional scaling (NMDS) using the Bray-Curtis index with 275 functions implemented in the 'vegan' package (Oksanen et al. 2015) for R (R Development Core 276 Team 2011). Specifically, NMDS was performed to analyse the effect of, for example, plant277 available phosphorus, carbon-to-nitrogen ratio, $\mathrm{pH}$ value $\left(\mathrm{pH} \mathrm{CaCl}_{2}\right)$ and humus content $(\mathrm{Table}$ 278 S3).

279

280 We conducted a transformation-based Redundancy Analysis (tb-RDA) to assess the effect of the 281 environmental parameters on the OTU distribution (Legendre \& Legendre 2012). Species 282 abundances were transformed using Hellinger transformation (Legendre \& Gallagher 2001) and 283 variables were selected using backward selection using functions from the 'vegan' package. 284 Additionally, a PERMANOVA was conducted (using the Bray-Curtis index) to test whether the 285 farming system has a significant influence on the OTU distribution (Anderson 2001). 


\section{Functional guilds}

288 We classified the identified taxa into ecological guilds with the FUNGuild tool and database [the 289 database is available at www.stbates.org/funguild_db.php, accessed 23 January 2020) (Nguyen et 290 al. 2016)], to determine if specific functional groups of fungi (e.g., pathotrophs, saprotrophs, 291 symbiotrophs, etc.) differed between sites and/or the farming methods applied. All OTUs that did 292 not match any taxa in the database were categorised as "unassigned".

Results

295

296

\section{PCR success and belowground fungal diversity}

A total of $54 \%$ of the pooled root samples yielded PCR products; 39 samples resulted positive 298 with the primer set ITS1F/ITS4 and 22 with NSI1/NL4, respectively (Table S2). Seven samples yielded strong bands but they were not directly sequenceable and, after cloning, the PCR produced only very few colonies. In total, 130 full-length non-chimeric ITS sequences clustered in 39 OTUs, 23 of which resulted in unique genotypes. In six cases, identical sequences for the same sample were obtained from both primer sets.

Belowground fungal communities were dominated by Ascomycota with 104 sequences (80\%) and Basidiomycota with 25 sequences (19.23\%), whereas the phylum Glomeromycota with one sequence (0.77\%) was less frequent (Fig. 2). When we clustered these sequences into OTUs, 24 
310 contained the most sequences and in the OTUs with the most sequences were the Basidiomycota $311 \# 35$ (four sequences), \#5, \#8 and \#0 (three sequences each). The most frequent OTUs, \#20 and

$312 \# 7$, were detected in seven and eight different samples from conventionally and organically

313 managed sites, respectively. The remaining OTUs were found either in a single sample or in up

314 to four different samples. Up to 12 different fungal sequences (\#20 on C2) from the same OTU

315 were generated from the same sample. Within each farming system, some OTUs were found in 316 samples along the entire transect. The OTUs show a nearly linear accumulation and the OTU 317 sampling did not reach saturation (Table 1). Out of all OTUs detected, 10 occurred exclusively in 318 conventional farms (three non-singletons) and 19 in organic farms (one non-singleton), whereas 31910 OTUs were present in both farming systems. Based on a comparison with reference 320 sequences, several OTUs have broadly disjunct distributions, either continental or locally 321 restricted. The diversity indices of the belowground fungal communities are given in Fig. 3.

322

323 Belowground fungal community composition

324 Belowground fungal communities from both conventional and organic farming systems showed 325 non-significant MPD values, whereas the MNTD values were significant for organic farming 326 systems only $(\mathrm{P}<0.05)$ (Table 1$)$.

327 328 Environmental factors of different farming systems

329 The main physical and chemical properties of the soils are shown in Table S3. The C/N ratios 330 were higher in soils under organic farming practices than those under conventional practices. On 331 the contrary, the related parameters total $\mathrm{N}$, total $\mathrm{C}$, organic $\mathrm{C}$, phosphorus and humus contents 332 had some values that overlapped between both management systems. Nonmetric 
333 multidimensional scaling (NMDS) showed the clear separation of farming systems according to

334 the soil parameters analysed (Fig. 4a).

335

336 Variable selection with tb-RDA identified three significant variables that account for $43.51 \%$ of 337 the variation (Ntotal $(\mathrm{p}=0.020)$, Stotal $(\mathrm{p}=0.035)$, Pcal $(\mathrm{p}=0.005))$ of the OTU distribution (Fig. 338 4b). The PERMANOVA, however, did identify the farming system as only having a minor 339 effect, while not being significant $\left(\mathrm{p}=0.086, \mathrm{R}^{2}=0.202\right)$.

340

\section{Functional guilds}

342 The fungal OTUs or species were grouped into 14 ecological guilds distributed across the

343 following trophic modes: pathotrophs (two OTUs), saprotrophs (four OTUs), symbiotrophs

344 (three OTUs), pathotroph-saprotrophs (six OTUs), pathotroph-symbiotrophs (four OTUs),

345 pathotroph-saprotroph-symbiotrophs (four OTUs) and those with an unknown position in the 346 food chain (16 OTUs) (Fig. 5 and Table 1). In general, a higher diversity of trophic modes 347 (involving some symbiotroph OTUs) were found on organically managed sites than in 348 conventional farming systems (Table 1).

\section{Discussion}

\section{Taxonomic coverage and belowground fungal community diversity}

The low number of PCR-positive samples obtained is possibly associated to the sample type 353 rather than to the primers' specificity and sensitivity. We combined two sets of primers since only seven samples were positive with both sets. The remaining samples were positive with only one primer set. We suspect that factors such as the inadequate disintegration of fine roots or the 
356 presence of inhibiting substances from the host plant could have affected the detection success of

357 fungi (PCR amplification) (see Schrader et al. 2012).

358

359 In this study, in roots of T. aestivum, up to eight different OTUs were identified per sample, 360 which indicates that the roots of one plant were colonised by several fungal species

361 simultaneously. Verbruggen et al. (2014) examined the fungal communities associated with 362 wheat roots from organically and conventionally managed farming sites in Switzerland. They 363 detected a remarkably greater number of OTUs (493) by sampling a smaller number of 364 individual wheat plants from a larger number of sites. The higher diversity detected in their study 365 may be partly caused by the different environmental conditions and sampling strategy, but was 366 primarily caused by the molecular methodology used: they applied next-generation sequencing, 367 in contrast to the Sanger sequencing we used here. Similar to this study, they identified most of 368 the detected fungi as Ascomycota, with two of the most common OTUs clustered within the 369 Sordariomycetes, and a few Basidiomycota (Fig. 2 and Table 1). Similarly, Carter et al. (1999), 370 who isolated fungi from the roots of field-grown wheat and used cultivation methods and 371 subsequent fungal characterisation by rDNA sequencing, found the Ascomycota to be more 372 frequent than the Basidiomycota.

373

374 Although the organic farming sites and two of the conventional farming sites were located within 375 short geographical distance from each other, each site had an almost unique OTU composition 376 and the overlap of OTUs was low (Fig. 3). Conversely, some OTUs were frequently detected 377 across several sampling sites, independent of the farming method. The OTU \#20, identified as 378 Microdochium sp., was more commonly detected in conventional than in organic sites. Members 
379 of the genus Microdochium are well known as plant pathogens which can cause head blight of

380 cereals (e.g. Xu et al. 2007). The fact that this fungus was isolated from roots of healthy wheat

381 plants confirms the common definition of endophytes, which also includes latent pathogens that

382 at some stage of their lifecycle inhabit plant tissues without causing apparent harm to their host

383 (Petrini 1991; Sun and Guo 2012). The OTU \#7 (without any assignment beyond Ascomycota in

384 the ITS RefSeq database) was closely related to Lasiosphaeriaceae spp. (sequences from 385 GenBank database) and it has also been isolated from roots of T. aestivum in Sweden 386 (Grudzinska-Sterno et al. 2016). Lasiosphaeriaceae spp. apparently include endophytic species 387 with a broad host range; some members of this fungal family have also been isolated as 388 endophytes of various host plants from diverse habitats (e.g., Arnold et al. 2000; Su et al. 2010). 389 In addition, OTU \#26, which was identified as Fusarium equiseti, was detected in all 390 conventional farming sites. $F$. equiseti is a ubiquitous soilborne pathogen that causes vascular 391 wilt on a wide spectrum of plants (Dean et al. 2012).

392

393 Impact of agricultural practices on belowground fungal communities

394 The present study revealed that the fungal communities are phylogenetically clustered and have 395 significant NRI values, indicating that each farming method contains a distinctive fungal 396 community (Table 2). Here, the farming method does influence the structure and also the fungal 397 OTU diversity. In particular, these results highlight that fungal community assembly could result 398 from similarities in response to some environmental factors, such as abiotic habitat filters, plant399 imposed habitat filters or interactions with other fungal species (Saunders et al. 2010). 400 Conventional farming systems, in contrast to organic systems, are characterised by the 401 application of agrochemicals, which can alter the soil's chemical composition and influence 
402 fungal diversity directly (Ellouze et al. 2014). Verbruggen et al. (2014) found that different 403 agricultural management practices did not have a significant effect on the fungal communities 404 associated with roots of T. aestivum, but they observed a significant effect of some abiotic soil 405 factors like $\mathrm{pH}$ and magnesium concentration. The results for this analysis were however 406 obtained by pooling sequences from different sites under the same management type, and further 407 studies with an increased replicate number would be needed to verify the results obtained here. 408 In this study, total $\mathrm{N}$, total $\mathrm{S}$ and Pcal explain around half of the variation in abundance and 409 composition of the fungal communities associated with winter wheat. Studying the long-term 410 effects of nitrogen and phosphorus fertilization on soil microbial community structure and 411 function under continuous wheat production, Li et al. (2019) observed that $\mathrm{N}$ fertilization 412 increased fungal abundance. Similarly, Jie et al. (2012) found that sulfur affects the composition 413 of arbuscular mycorrhizal fungal communities of different soybean cultivars. Cai et al. (2019) 414 working with a rice-fish system found that total $\mathrm{N}$ and available $\mathrm{P}$ regulated the abundance of 415 dominant fungi. When assessing the influence of the farming method directly, however, only a 416 weak (and non-significant) effect could be observed, which could indicate that the underlying 417 soil parameters play a stronger role than the type of management (REF).

419 One of the most striking differences between sampling sites from the two farming systems was 420 the abundance and diversity of the co-occurring vegetation, which was generally higher in 421 organic farming sites. As the OTU diversity was similarly high in organic sites, we postulate that 422 the co-occurring vegetation could serve as a reservoir source of some fungal taxa. Verbruggen et 423 al. (2014) examined the diversity of co-occurring weed communities and their ability to 424 significantly influence fungal diversity and suggested that this might be partly a result of the 
425 weed litter left in the soil, which could stimulate the growth of endophytes with saprobic activity.

426 Furthermore, they suggest the influence of the co-occurring plant community if some endophytic

427 fungi with a broad host range proliferate more extensively in neighboring plant species than in

428 wheat itself. Besides that, there is evidence that plants release a wide array of compounds via

429 their roots that can act as nutrient sources for soil fungi and can stimulate their proliferation

430 (Ellouze et al. 2014). Therefore, a wide array of co-occurring plant species that release equally

431 diverse compounds may provide a basis for the establishment of a wide array of fungi. Riess

432 (2009) studied endophytes associated with cereals, including T. aestivum, and the co-occurring

433 herbaceous plant species and observed that in many cases, the neighboring plants were colonised

434 by the same fungal phylotype. This author suggested that the associated fungi could connect their

435 host plants in belowground networks in a similar manner to ectomycorrhizal (Onguene \&

436 Kuyper 2002) or arbuscular mycorrhizal fungi (Voets et al. 2009). This could also be supported

437 by the fact that a great number of endophytic fungal species are primarily transmitted

438 horizontally (Rodriguez et al. 2009).

439

440 The predicted functional guilds of the fungal sequences also varied between conventionally and

441 organically grown winter wheat (Fig. 5 and Table 1). Interestingly, an increase in the occurrence

442 of potential plant pathogen fungi and a decrease in the symbiotrophs were predicted for organic

443 farming. The fact that fungal orders containing mainly endophytic species were detected in the

444 roots, as well as mycorrhizal, parasitic or saprobic species, is not surprising. For instance,

445 members of the Glomeromycota, which comprise arbuscular mycorrhizal fungi and were

446 detected twice in this study, can typically grow within plant roots (Parniske 2008). Additionally,

447 it is difficult to distinguish fungal species on the basis of their lifestyles, because some species 
448 change their ecological strategy during their lifecycle. For example, there is evidence that some

449 endophytes can also adopt saprobic lifestyles at senescence of their host plant (Promputtha et al.

450 2007; Porras-Alfaro \& Bayman 2011).

451

452 Conclusions

453 In conclusion, our results show that the fungal communities associated with winter wheat are 454 affected in their diversity, composition and functionality by the agricultural practices. We 455 identify total $\mathrm{N}$, total $\mathrm{S}$ and Pcal as having a significant effect on the OTU's abundance and 456 distribution, but a large part of the variation within the studied communities remains unexplained 457 by these factors. It seems likely that a correlation with the abundance and/or diversity of the co458 occurring vegetation exists. Further studies that include a larger number of samples and apply 459 integrated molecular and culture-based methods are needed. With this strategy, it would be 460 possible to analyse the phylogenetic diversity and composition of the fungal communities more 461 accurately in larger-scale comparisons of different faming systems. These studies should also 462 address the role of the co-occurring vegetation in correlation with the fungal diversity and 463 functionality associated with the roots of T. aestivum. Finally, the data obtained could be used to 464 identify fungal species with beneficial effects on the fitness of T. aestivum and their potential to 465 be used as organic fertilisers for agriculture.

466

467 Acknowledgements

468 We thank S. Silberhorn and P. Weiss for assistance with the laboratory work. We are very 469 grateful to the farmers U. Bechtle (Unterjesingen) and E. Wizemann (Entringen, Pfrondorf) for 470 allowing us to collect plant specimens from their crop fields.

471

472 References 
473 Ad-hoc-Arbeitsgruppe Boden, 2005. Bodenkundliche Kartieranleitung: Ad-hoc-Arbeitsgruppe 474 Boden der Geologischen Landesämter und der Bundesanstalt für Geowissenschaften und 475 Rohstoffe der Bundesrepublik Deutschland. Schweizerbart Sche Vlgsb. ISBN 10: 3510959205, 476 ISBN 13: 9783510959204.

477

478 Anderson MJ, 2001. A new method for non-parametric multivariate analysis of variance. Austral 479 Ecology 26: 32-46.

480

481 Arnold AE, Maynard Z, Gilbert GS, Coley PD, Kursar TA, 2000. Are tropical fungal endophytes 482 hyperdiverse? Ecology Letters 3(4): 267-274.

483

484 Cai S, Lv W, Zhu H, Zhang D, Fu Z, Zhang H, Xu S, 2019. Effect of nitrogen application rate on 485 soil fungi community structure in a rice-fish mutualistic system. Scientific Reports 9:16188 486 https://doi.org/10.1038/s41598-019-52602-x

487

488 Carter JP, Spink J, Cannon PF, Daniels MJ, Osbourn AE, 1999. Isolation, characterization, and 489 avenacin sensitivity of a diverse collection of cereal-root-colonizing fungi. Applied and 490 Environmental Microbiology 65 (8): 3364-3372.

491

492 Dean R, Van Kan JA, Pretorius ZA, Hammond-Kosack KE, Di Pietro A, Spanu PD, Rudd JJ, 493 Dickman M, Kahmann R, Ellis J, Foster GD, 2012. The top 10 fungal pathogens in molecular 494 plant pathology. Molecular Plant Pathology 13: 414-30. 
496 Edgar RC, 2010. Search and clustering orders of magnitude faster than BLAST. Bioinformatics 497 26: 2460-2461.

498

499 Edgar RC, Haas BJ, Clemente JC, Quince C, Knight R, 2011. UCHIME improves sensitivity and 500 speed of chimera detection. Bioinformatics 27: 2194-2200.

501

502 Ellouze W, Taheri AE, Bainard LD, Yang C, Bazghaleh N, Navarro-Borrell A, Hanson K, 503 Hamel C, 2014. Soil fungal resources in annual cropping systems and their potential for 504 management. Biomed Research International ID 531824. doi.org/10.1155/2014/531824

505

506 Gardes M, Bruns TD, 1993. ITS primers with enhanced specificity for basidiomycetes 507 application to the identification of mycorrhizae and rusts. Molecular Ecology 2(2): 113-118.

508

509 Gomiero T, Pimentel D, Paolett MG, 2011. Environmental impact of different agricultural 510 management practices: conventional vs. organic agriculture. Critical Review in Plant Sciences 511 30: 95-124.

512

513 Grudzinska-Sterno M, Yuen J, Stenlid J, Djurle A, 2016. Fungal communities in organically 514 grown winter wheat affected by plant organ and development stage. European Journal of Plant 515 Pathology 146: 401-417. doi: 10.1007/s10658-016-0927-5.

516 
517 Gryndler M, Larsen J, Hrselova H, Rezacova V, Gyndlerova H, Kubat J, 2006. Organic and 518 mineral fertilization, respectively, increase and decrease the development of external mycelium 519 of arbuscular mycorrhizal fungi in a long-term field experiment. Mycorrhiza 16: 159-166.

520

521 Gurulingappa P, Sword GA, Murdoch G, McGee PA, 2010. Colonization of crop plants by 522 fungal entomopathogens and their effects on two insect pests when in plants. Biological Control $52355(1): 34-41$.

524

525 Herbig A, Maixner F, Bos KI, Zink A, Krause J, Huson DH, 2016. MALT: Fast alignment and 526 analysis of metagenomic DNA sequence data applied to the Tyrolean Iceman. bioRxiv 527 doi:10.1101/050559.

528

529 Hubbard M, Germida JJ, Vujanovic V, 2014. Fungal endophytes enhance wheat heat and 530 drought tolerance in terms of grain yield and second-generation seed viability. Journal of 531 Applied Microbiology 116(1): 109-122.

532

533 Jie W, Cai B, Zhang Y, Li J, Ge J, 2012. The effect of sulfur on the composition of arbuscular 534 mycorrhizal fungal communities during the pod-setting stage of different soybean cultivars. Curr 535 Microbiol. 65(5):500-506. doi:10.1007/s00284-012-0183-7

536

537 Kembel SW, Cowan PD, Helmus MR, Cornwell WK, Morlon H, Ackerly DD, Blomberg SP, 538 Webb CO, 2010. Picante: R tools for integrating phylogenies and ecology. Bioinformatics 539 26:1463-1464. 
540

541 Larran S, Perello A, Simon MR, Moreno V, 2007. The endophytic fungi from wheat (Triticium

542 aestivum L). World Journal of Microbiology and Biotechnology 23(4): 565-572.

543

544 Legendre P, Gallagher ED, 2001. Ecologically meaningful transformations for ordination of 545 species data. Oecologia 129: 271-280.

546

547 Legendre P, Legendre L, 2012. Numerical Ecology. 3rd English ed. Elsevier.

548

549 Leimeister CA, Boden M, Horwege S, Lindner S, Morgenstern B, 2014. Fast alignment-free 550 sequence comparison using spaced-word frequencies. Bioinformatics 30: 1991-1999.

551

552 Li Y, Tremblay J, Bainard L, Cade-Menun B, Hamel C, 2019. Long-term effects of nitrogen and 553 phosphorus fertilization on soil microbial community structure and function under continuous 554 wheat production. Environmental Microbiology 22(3). doi: 10.1111/1462-2920.14824.

555

556 Mäder P, Fließbach A, Dubois D, Gunst L, Fried P, Niggli U, 2002. Soil fertility and biodiversity 557 in organic farming. Science 296: 1694-1697.

558

559 Martin KJ, Rygiewicz PT, 2005. Fungal-specific PCR primers developed for analysis of the ITS 560 region of environmental DNA extracts. BMC Microbiology 5: 28. doi: 10.1186/1471-2180-5-28 
562 Nguyen NH, Song Z, Bates ST, Branco S, Tedersoo L, Menke J, Schillinge JS, Kennedy PG, 563 2016. FUNGuild: An open annotation tool for parsing fungal community datasets by ecological 564 guild. Fungal Ecology 20: 241-248. doi.org/10.1016/j.funeco.2015.06.006

565

566 Oehl F, Sieverding E, Mäder P, Dubois D, Ineichen K, Boller T, Wiemken A, 2004. Impact of 567 long-term conventional and organic farming on the diversity of arbuscular mycorrhizal fungi. 568 Oecologia 138: 574-583. doi: 10.1007/s00442-003-1458-2

569

570 O'Hanlon KA, Knorr K, Jorgensen LN, Nicolaisen M, Boelt B, 2012. Exploring the potential of 571 symbiotic fungal endophytes in cereal disease suppression. Biological Control 63(2): 69-78.

572

573 Oksanen J, Blanchet FG, Kindt R, Legendre P, Minchin PR, O’Hara RB, Simpson GL, Solymos 574 P, Henry M, Stevens H, Szoecs E, Wagner H, 2016. vegan: Community Ecology Package. R 575 package version 2.3-5. https://cran.r-project.org, https://github.com/vegandevs/vegan

576

577 Onguene N, Kuyper T, 2002. Importance of the ectomycorrhizal network for seedling survival 578 and ectomycorrhiza formation in rain forests of south Cameroon. Mycorrhiza 12(1): 13-17.

579

580 Parniske M, 2008. Arbuscular mycorrhiza: the mother of plant root endosymbioses. Nature 581 Reviews Microbiology 6(10): 763-775.

582

583 Petrini O, 1991. Fungal endophytes of tree leaves. In: Andrews J. and Hirano S. (Eds.), 584 Microbial Ecology of Leaves, Springer, New York: 179-197. 
585

586 Porras-Alfaro A, Bayman P, 2011. Hidden fungi, emergent properties: endophytes and 587 microbiomes. Annual Review of Phytopathology 49(1): 291-315.

588

589 Promputtha I, Lumyong S, Dhanasekaran V, McKenzie E, Hyde K, Jeewon R, 2007. A 590 phylogenetic evaluation of whether endophytes become saprotrophs at host senescence. 591 Microbial Ecology 53(4): 579-590.

592

593 R Development Core Team, 2011. R: A language and environment for statistical computing. R 594 Foundation for Statistical Computing, Vienna. http://www.R-project.org.

595

596 Rabiey M, Ullah I, Shaw MW, 2015. The endophytic fungus Piriformospora indica protects 597 wheat from Fusarium crown rot disease in simulated UK autumn conditions. Plant Pathology 598 64: 1029-1040. doi: 10.111/ppa.12335.

599

600 Riess K, 2009. Endophytische Sebacinales assoziiert mit Getreide und dessen Begleitpflanzen. 601 Diploma Thesis, Eberhard-Karls-University, Tübingen.

602

603 Riess K, Oberwinkler F, Bauer R, Garnica S, 2014. Communities of endophytic Sebacinales 604 associated with roots of herbaceous plants in agricultural and grassland ecosystems are 605 dominated by Serendipita herbamans sp. nov. PLoS ONE 9: e94676. 606 doi:10.1371/journal.pone.0094676

607 
608 Rodriguez RJ, White JrJF, Arnold AE, Redman RS, 2009. Fungal endophytes: diversity and 609 functional roles. New Phytologist 182(2): 314-330.

610

611 Rognes T, Flouri T, Nichols B, Quince C, Mahé F, 2016. VSEARCH: a versatile open source 612 tool for metagenomics. PeerJ 18(4): e2584.

613

614 Saunders M, Glenn AE, Kohn LM, 2010. Exploring the evolutionary ecology of fungal 615 endophytes in agricultural systems: using functional traits to reveal mechanisms in community 616 processes. Evolutionary Applications 3(5-6): 525-537.

617

618 Schrader C, Schielke A, Ellerbroek L, Johne R, 2012. PCR inhibitors - occurrence, properties

619 and removal. Journal of Applied Microbiology 113: 1014-1026. doi.org/10.1111/j.1365$620 \quad 2672.2012 .05384 . x$

621

622 Seghers D, Wittebolle L, Top EM, Verstraete W, Siciliano SD, 2004. Impact of agricultural 623 practices on the Zea mays L. endophytic community. Applied Environmental Microbiology 70: $624 \quad 1475-1482$.

625

626 Shannon D, Sen AM, Johnson DB, 2002. A comparative study of the microbiology of soils 627 managed under organic and conventional regimes. Soil Use and Management 18: 274-283.

628 
629 Statistisches Bundesamt Wiesbaden, 2014. Betriebe mit ökologischem Landbau. 630 Agrarstrukturerhebung. Land- und Forstwirtschaft, Fischerei Fachserie 3 (Reihe 2.2.1). (C) 631 Statistisches Bundesamt (Destatis).

632

633 Statistisches Bundesamt Wiesbaden, 2015. Pressemitteilung Nr. 181 vom 19.05.2015. 634 Retrieved 19 July 2015.

635

$636 \mathrm{Su}$ Y-Y, Guo L-D, Hyde K, 2010. Response of endophytic fungi of Stipa grandis to 637 experimental plant function group removal in Inner Mongolia steppe, China. Fungal Diversoty 638 43(1): 93-101.

639

640 Sun L, Qiu F, Zhang X, Dai X, Dong X, Song W, 2008. Endophytic bacterial diversity in rice 641 (Oryza sativa L.) roots estimated by 16S rDNA sequence analysis. Microbial Ecology 55(3): $642 \quad 415-424$.

643

644 Sun X, Guo L-D, 2012. Endophytic fungal diversity: review of traditional and molecular 645 techniques. Mycology 3(1): 65-76.

646

647 Tautges NE, Sullivan TS, Reardon CL, Burke IC, 2016. Soil microbial diversity and activity 648 linked to crop yield and quality in a dryland organic wheat production system. Applied Soil 649 Ecology 108: 258-268. doi: 10.1016/j.apsoil.2016.09.003 
651 Tilman D, Balzer C, Hill J, Befort BL, 2011. Global food demand and the sustainable

652 intensification of agriculture. Proceedings of the National Academy of Sciences USA

653 108(50): 20260-20264. doi:10.1073/pnas.1116437108

654

655 Verbruggen E, Rillig MC, Wehner J, Hegglin D, Wittwer R, van der Heijden MGA, 2014.

656 Sebacinales, but not total root associated fungal communities, are affected by land-use intensity.

657 New Phytologist 203: 1036-1040. doi:10.1111/nph.12884

658

659 Vilgalys R, Hester M, 1990. Rapid genetic identification and mapping of enzymatically 660 amplified ribosomal DNA from several Cryptococcus species. Journal of Bacteriology 172(8): $6614238-4246$.

662

663 Voets L, de la Providencia I, Fernandez K, Ijdo M, Cranenbrouck S, Declerck S, 2009. 664 Extraradical mycelium network of arbuscular mycorrhizal fungi allows fast colonization of 665 seedlings under in vitro conditions. Mycorrhiza 19(5): 347-356.

666

667 Webb CO, Ackerly DD, McPeek MA, Donoghue MJ, 2002. Phylogenies and community 668 ecology. Annual Review of Ecology and Systematics 33: 475-505.

669

670 White TJ, Bruns S, Lee S, Taylor J, 1990. Amplification and direct sequencing of fungal 671 ribosomal RNA genes for phylogenetics. In: Innis MA, Gelfand DH, Sninsky JJ, White TJ 672 (Eds.), PCR Protocols. A Guide to Methods and Applications, Academic Press, San Diego, pp. $673 \quad 315-322$. 
674

$675 \mathrm{Xu}$ XM, Nicholson P, Thomsett MA, Simpson D, Cooke BM, Doohan FM, Brennan J, 676 Monaghan S, Moretti A, Mule G, Hornok L, Beki E, Tatnell J, Ritieni A, Edwards SG, 2007.

677 Relationship between the fungal complex causing Fusarium head blight of wheat and 678 environmental conditions. Phytopathology 98(1): 69-78.

679

680 Zarb J, Ghorbani R, Koocheki A, Leifert C, 2005. The importance of microorganisms in organic 681 agriculture. Outlooks on Pest Management 16: 52-55. doi: 10.1564/16ap102. 


\section{Figure 1}

Geographic locations of the sampling sites of winter wheat (Triticum aestivum) around Tübingen (Germany), including two conventional farming sites

(a) Overview: conventional farming (C) Entringen (b) and Pfrondorf (c) and organic farming (0) in Unterjesingen (d) [Map data: @ 2015 Google, @ 2009 GeoBasis-DE/BKG] Detailed view of the sampling sites: (b) two sites in Entringen [Map Data: Google Earth], (c) three sites in Pfrondorf [Map Data: Google Earth], and (d) five sites in Unterjesingen [Map Data: Google Earth] respectively. 


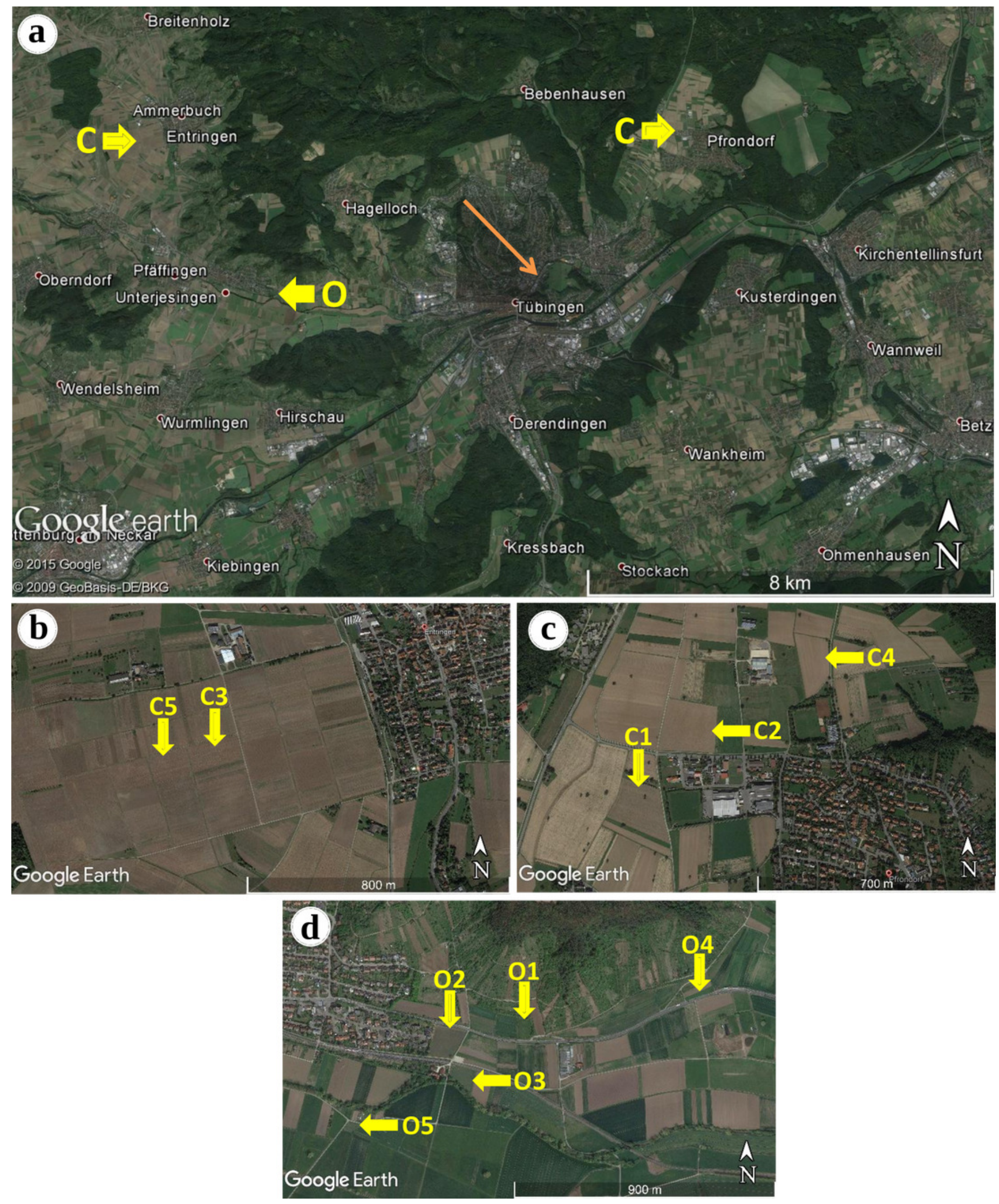


Figure 2

Taxonomic distribution at order level of fungal sequences associated with roots of winter wheat (Triticum aestivum) based on similarity searches against the fungal ResSeq database.

(A) Ascomycota, (B) Basidiomycota and (G) Glomeromycota.

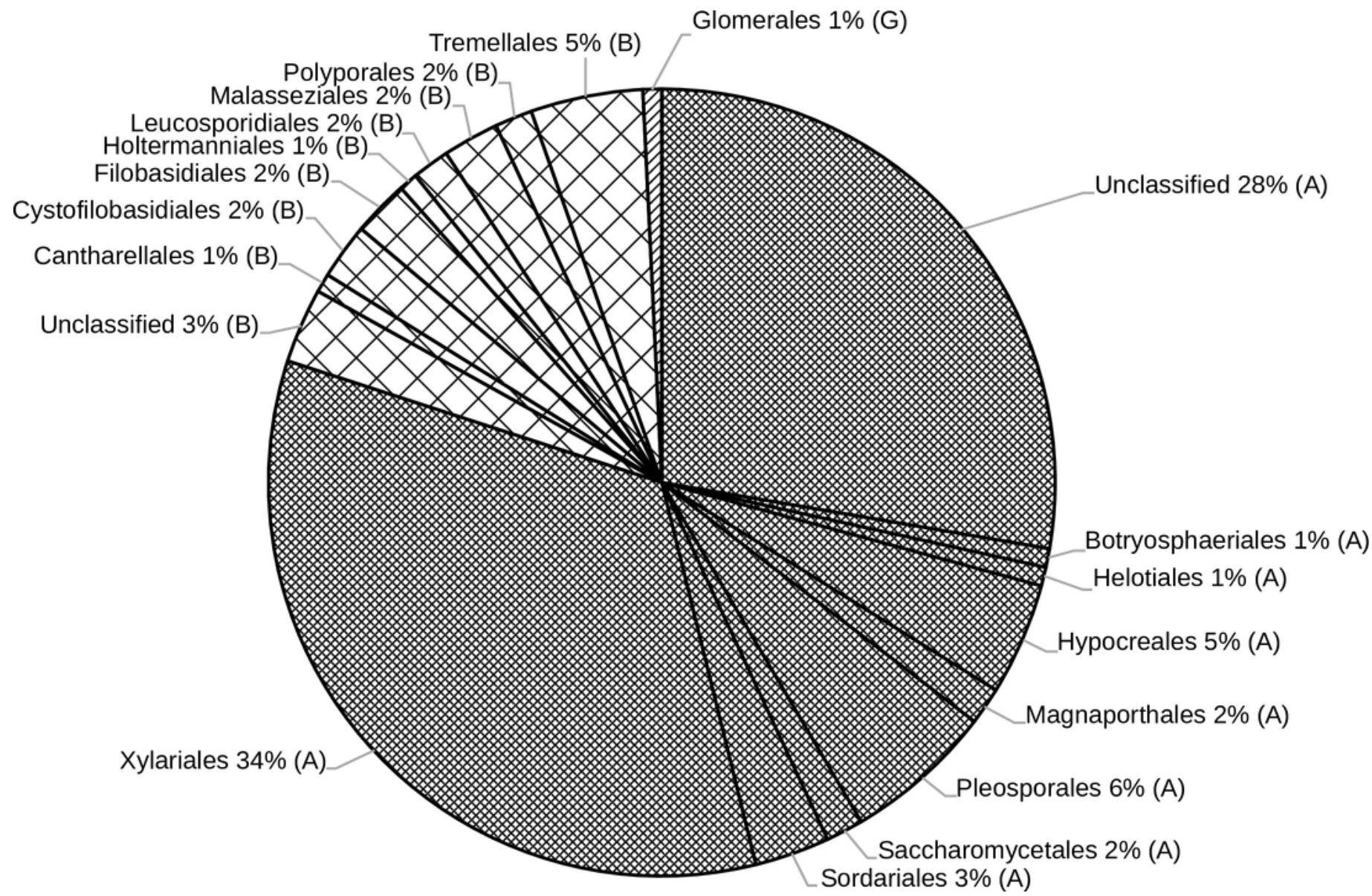


Figure 3

Alpha-diversity ( $y$-axis) of belowground fungal communities associated with roots of winter wheat (Triticum aestivum) from organic and conventional farming systems.

For each farming system, the Hill numbers for different values of $q$ (order of diversity, $x$-axis) were calculated, giving different weights to species abundances. Green dotted lines show the minimum and maximum across all samples; pink dotted lines show the average.

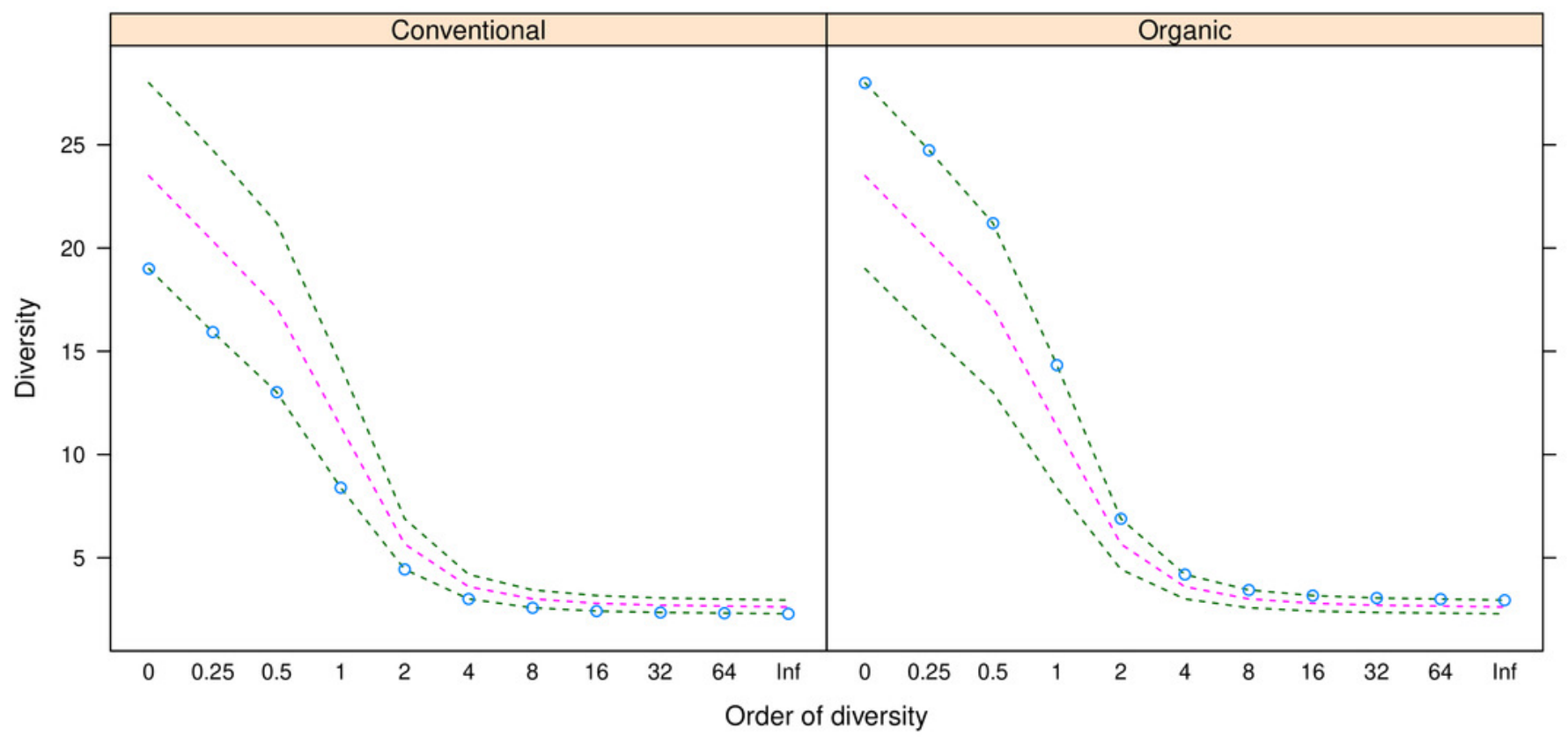




\section{Figure 4}

Ordination analyses.

a) Non-metric multidimensional scaling plot of sampling sites based on their environmental parameters. Polygons show the connections of plots from organic (blue) and conventional (red) sites. b) tb-RDA analysis of the fungal communities and the environmental variables associated with organic (blue) and conventional (red) sampling plots. Using variable selection, three environmental parameters (Nt, St, Pcal) were detected as having a significant effect on the fungal communities, and together accounted for $43.51 \%$ of the observed variation. Pcal: with Calcium-Acetate-Lactate extracted Phosphorus, Kcal: with Calcium-Acetate-Lactate extracted Potassium, Nt: Nitrogen total, Ct: carbon total, $\mathrm{pHCaCl2:}$ soil pH, St: Sulfur total, Corg: Carbon organic, C/N: Carbon-to-Nitrogen ratio and Humus: humus content.

a)

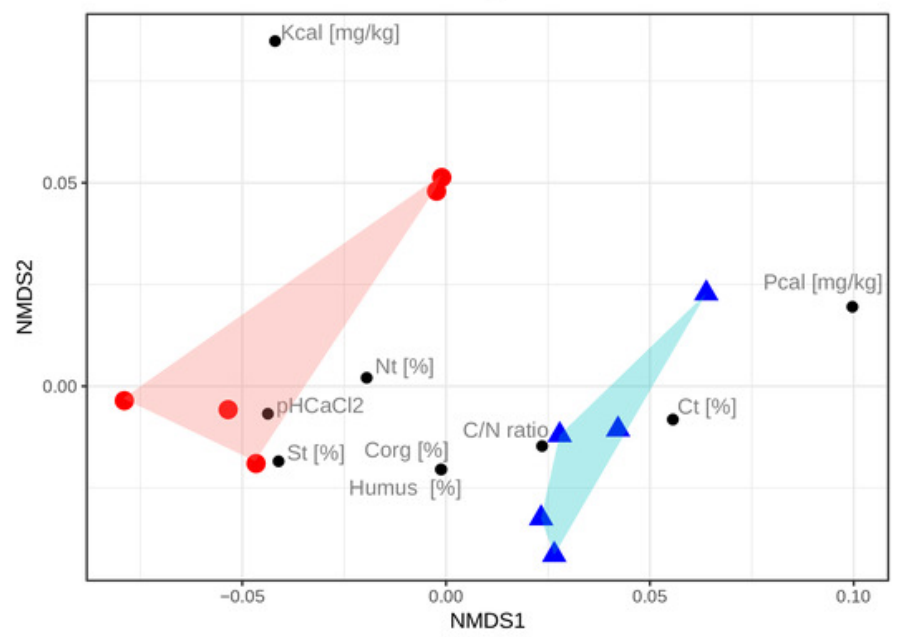

b)

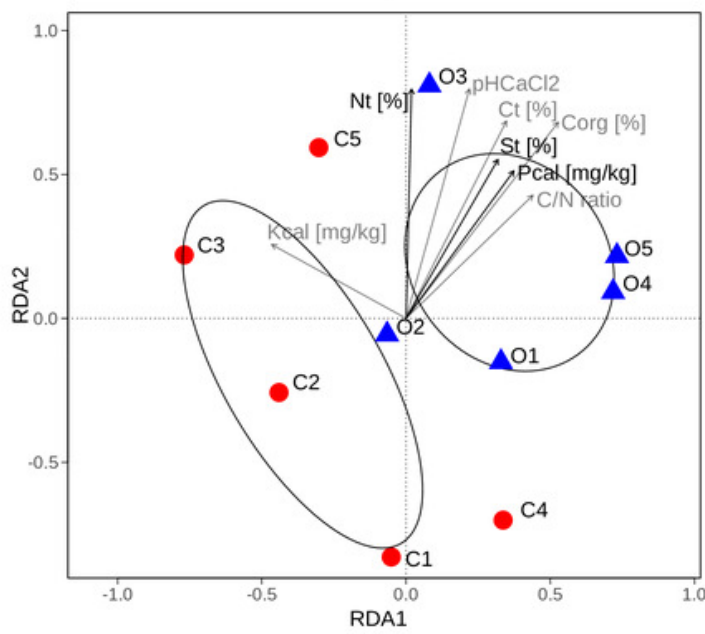

Farming system

- Conventional

$\Delta$ Organic 


\section{Figure 5}

Ecological guilds of the fungal taxa in belowground communities associated with the roots of winter wheat (Triticum aestivum) from organic and conventional farming systems.

The fungal taxa were classified into 16 ecological guilds with the FUNGuild tool and database. The value in parentheses and the position on the $x$-axis indicate the number of individual sequences associated with that guild. 
Endophyte-Plant Pathogen (44)

Animal Pathogen-Endophyte-Lichen Parasite-Plant Pathogen-Soil Saprotroph-Wood Saprotroph (6)

Fungal Parasite-Undefined Saprotroph (6)

Undefined Saprotroph (5)

Animal Pathogen-Undefined Saprotroph (3)

Leaf Saprotroph (3)

Plant Pathogen (2)

Dung Saprotroph-Endophyte-Litter Saprotroph-Undefined Saprotroph (2)

Dung Saprotroph (2)

Fungal Parasite-Plant Pathogen-Plant Saprotroph (1)

Ectomycorrhizal (1)

Endophyte-Plant Pathogen-Wood Saprotroph (1)

Arbuscular Mycorrhizal (1)

Fungal Parasite-Plant Pathogen (1)

Endophyte (1)

Animal Pathogen-Plant Pathogen-Undefined Saprotroph (1)

Unassigned (50)

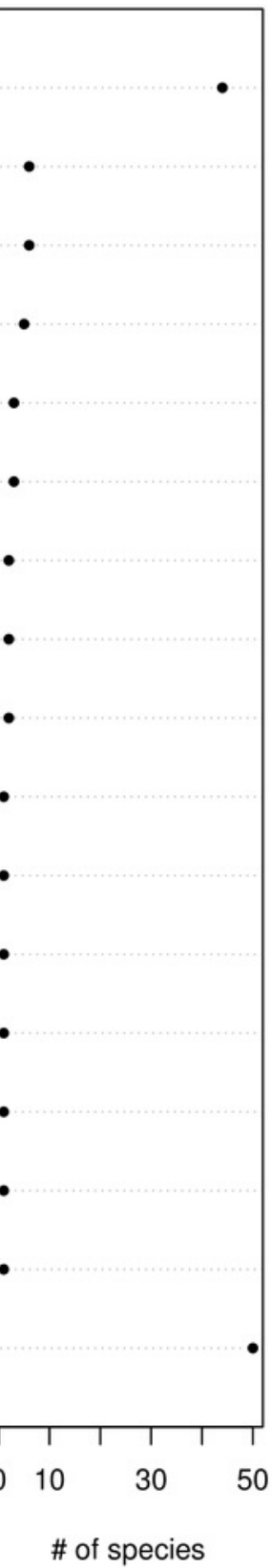




\section{Table $\mathbf{1}$ (on next page)}

Taxonomic identifications based on similarity searches against the fungal RefSeq database for fungal sequences associated with the roots of winter wheat (Triticum aestivum) from sites under organic and conventional management.

The accession numbers of sequences from this study are given as well as the assigned molecular operational taxonomic unit (MOTU), taxonomic information and ecological guild. Further Information can also be found in Supplementary Table 4. 


\begin{tabular}{|c|c|c|c|c|}
\hline sequence ID & MOTU & species & trophic mode & farming system \\
\hline KY430446 & 7 & $\begin{array}{l}\text { Helotiales incertae } \\
\text { sedis }\end{array}$ & - & Conventional \\
\hline KY430447 & 7 & Ascomycota & - & Organic \\
\hline KY430448 & 7 & Ascomycota & - & Organic \\
\hline KY430449 & 7 & Ascomycota & - & Organic \\
\hline KY430451 & 19 & Schizothecium & Saprotroph & Conventional \\
\hline KY430452 & 38 & Candida sake & Saprotroph & Organic \\
\hline KY430453 & 38 & Candida sake & Saprotroph & Organic \\
\hline KY430454 & 27 & Pleosporineae & - & Conventional \\
\hline KY430455 & 29 & Didymellaceae & $\begin{array}{l}\text { Pathotroph- } \\
\text { Saprotroph }\end{array}$ & Conventional \\
\hline KY430456 & 28 & Pleosporineae & - & Organic \\
\hline KY430457 & 20 & Microdochium & $\begin{array}{l}\text { Pathotroph- } \\
\text { Symbiotroph }\end{array}$ & Organic \\
\hline KY430458 & 20 & Microdochium & $\begin{array}{l}\text { Pathotroph- } \\
\text { Symbiotroph }\end{array}$ & Conventional \\
\hline KY430459 & 20 & Microdochium & $\begin{array}{l}\text { Pathotroph- } \\
\text { Symbiotroph }\end{array}$ & Conventional \\
\hline KY430460 & 20 & Microdochium & $\begin{array}{l}\text { Pathotroph- } \\
\text { Symbiotroph }\end{array}$ & Conventional \\
\hline KY430461 & 20 & Microdochium & $\begin{array}{l}\text { Pathotroph- } \\
\text { Symbiotroph }\end{array}$ & Conventional \\
\hline KY430462 & 20 & Microdochium & $\begin{array}{l}\text { Pathotroph- } \\
\text { Symbiotroph }\end{array}$ & Organic \\
\hline KY430463 & 35 & $\begin{array}{l}\text { Vishniacozyma } \\
\text { victoriae }\end{array}$ & $\begin{array}{l}\text { Pathotroph- } \\
\text { Saprotroph- } \\
\text { Symbiotroph }\end{array}$ & Organic \\
\hline KY430465 & 6 & Agaricomycetes & - & Organic \\
\hline KY430466 & 35 & $\begin{array}{l}\text { Vishniacozyma } \\
\text { victoriae }\end{array}$ & $\begin{array}{l}\text { Pathotroph- } \\
\text { Saprotroph- } \\
\text { Symbiotroph }\end{array}$ & Conventional \\
\hline KY430467 & 5 & Filobasidium & Saprotroph & Conventional \\
\hline KY430468 & 5 & Filobasidium & Saprotroph & Organic \\
\hline KY430469 & 20 & Microdochium & $\begin{array}{l}\text { Pathotroph- } \\
\text { Symbiotroph }\end{array}$ & Conventional \\
\hline KY430470 & 20 & Microdochium & Pathotroph- & Conventional \\
\hline
\end{tabular}




\begin{tabular}{|c|c|c|c|c|}
\hline sequence ID & MOTU & species & trophic mode & farming system \\
\hline & & & Symbiotroph & \\
\hline KY430471 & 7 & Ascomycota & - & Organic \\
\hline KY430472 & 31 & Darksidea & Symbiotroph & Organic \\
\hline KY430473 & 26 & Fusarium equiseti & $\begin{array}{l}\text { Pathotroph- } \\
\text { Saprotroph- } \\
\text { Symbiotroph }\end{array}$ & Conventional \\
\hline KY430474 & 36 & Ascomycota & - & Organic \\
\hline KY430475 & 20 & Microdochium & $\begin{array}{l}\text { Pathotroph- } \\
\text { Symbiotroph }\end{array}$ & Organic \\
\hline KY430476 & 26 & Fusarium equiseti & $\begin{array}{l}\text { Pathotroph- } \\
\text { Saprotroph- } \\
\text { Symbiotroph }\end{array}$ & Conventional \\
\hline KY430477 & 26 & Fusarium equiseti & $\begin{array}{l}\text { Pathotroph- } \\
\text { Saprotroph- } \\
\text { Symbiotroph }\end{array}$ & Conventional \\
\hline KY430478 & 33 & Podospora & $\begin{array}{l}\text { Saprotroph- } \\
\text { Symbiotroph }\end{array}$ & Organic \\
\hline KY430479 & 8 & $\begin{array}{l}\text { Cystofilobasidium } \\
\text { macerans }\end{array}$ & Saprotroph & Organic \\
\hline KY430480 & 20 & Microdochium & $\begin{array}{l}\text { Pathotroph- } \\
\text { Symbiotroph }\end{array}$ & Conventional \\
\hline KY430481 & 4 & Polyporales & - & Organic \\
\hline KY430482 & 11 & Botryosphaeriales & - & Organic \\
\hline KY430483 & 13 & Lentitheciaceae & - & Organic \\
\hline KY430484 & 5 & Filobasidium & Saprotroph & Organic \\
\hline KY430485 & 7 & Ascomycota & - & Organic \\
\hline KY430487 & 24 & Leotiomycetes & - & Organic \\
\hline KY430488 & 7 & Ascomycota & - & Organic \\
\hline KY430489 & 30 & Ascomycota & - & Organic \\
\hline KY430490 & 15 & $\begin{array}{l}\text { Helminthosporium } \\
\text { velutinum }\end{array}$ & Pathotroph & Organic \\
\hline KY430491 & 34 & $\begin{array}{l}\text { Vishniacozyma } \\
\text { tephrensis }\end{array}$ & $\begin{array}{l}\text { Pathotroph- } \\
\text { Saprotroph- } \\
\text { Symbiotroph }\end{array}$ & Organic \\
\hline KY430492 & 7 & Ascomycota & - & Conventional \\
\hline KY430493 & 20 & Microdochium & Pathotroph- & Conventional \\
\hline
\end{tabular}




\begin{tabular}{|c|c|c|c|c|}
\hline sequence ID & MOTU & species & trophic mode & farming system \\
\hline & & & Symbiotroph & \\
\hline KY430494 & 20 & Microdochium & $\begin{array}{l}\text { Pathotroph- } \\
\text { Symbiotroph }\end{array}$ & Organic \\
\hline KY430496 & 7 & Ascomycota & - & Organic \\
\hline KY430497 & 20 & Microdochium & $\begin{array}{l}\text { Pathotroph- } \\
\text { Symbiotroph }\end{array}$ & Conventional \\
\hline KY430498 & 14 & $\begin{array}{l}\text { Funneliformis } \\
\text { mosseae }\end{array}$ & Symbiotroph & Organic \\
\hline KY430499 & 7 & Ascomycota & - & Organic \\
\hline KY430500 & 35 & $\begin{array}{l}\text { Vishniacozyma } \\
\text { victoriae }\end{array}$ & $\begin{array}{l}\text { Pathotroph- } \\
\text { Saprotroph- } \\
\text { Symbiotroph }\end{array}$ & Conventional \\
\hline KY430501 & 7 & Ascomycota & - & Conventional \\
\hline KY430502 & 7 & Ascomycota & - & Organic \\
\hline KY430503 & 20 & Microdochium & $\begin{array}{l}\text { Pathotroph- } \\
\text { Symbiotroph }\end{array}$ & Conventional \\
\hline KY430504 & 7 & Ascomycota & - & Organic \\
\hline KY430505 & 20 & Microdochium & $\begin{array}{l}\text { Pathotroph- } \\
\text { Symbiotroph }\end{array}$ & Conventional \\
\hline KY430506 & 20 & Microdochium & $\begin{array}{l}\text { Pathotroph- } \\
\text { Symbiotroph }\end{array}$ & Conventional \\
\hline KY430507 & 20 & Microdochium & $\begin{array}{l}\text { Pathotroph- } \\
\text { Symbiotroph }\end{array}$ & Conventional \\
\hline KY430508 & 20 & Microdochium & $\begin{array}{l}\text { Pathotroph- } \\
\text { Symbiotroph }\end{array}$ & Conventional \\
\hline KY430509 & 12 & $\begin{array}{l}\text { Slopeiomyces } \\
\text { cylindrosporus }\end{array}$ & Pathotroph & Organic \\
\hline KY430510 & 22 & Microdochium & $\begin{array}{l}\text { Pathotroph- } \\
\text { Symbiotroph }\end{array}$ & Organic \\
\hline KY430511 & 22 & Microdochium & $\begin{array}{l}\text { Pathotroph- } \\
\text { Symbiotroph }\end{array}$ & Organic \\
\hline KY430512 & 19 & Schizothecium & Saprotroph & Conventional \\
\hline KY430514 & 20 & Microdochium & $\begin{array}{l}\text { Pathotroph- } \\
\text { Symbiotroph }\end{array}$ & Organic \\
\hline KY430515 & 9 & $\begin{array}{l}\text { Leucosporidium } \\
\text { golubevii }\end{array}$ & - & Organic \\
\hline
\end{tabular}




\begin{tabular}{|c|c|c|c|c|}
\hline sequence ID & MOTU & species & trophic mode & farming system \\
\hline KY430516 & 20 & Microdochium & $\begin{array}{l}\text { Pathotroph- } \\
\text { Symbiotroph }\end{array}$ & Organic \\
\hline KY430517 & 21 & Periconia & $\begin{array}{l}\text { Pathotroph- } \\
\text { Saprotroph- } \\
\text { Symbiotroph }\end{array}$ & Organic \\
\hline KY430518 & 7 & Ascomycota & - & Organic \\
\hline KY430519 & 12 & $\begin{array}{l}\text { Slopeiomyces } \\
\text { cylindrosporus }\end{array}$ & Pathotroph & Organic \\
\hline KY430520 & 20 & Microdochium & $\begin{array}{l}\text { Pathotroph- } \\
\text { Symbiotroph }\end{array}$ & Organic \\
\hline KY430521 & 20 & Microdochium & $\begin{array}{l}\text { Pathotroph- } \\
\text { Symbiotroph }\end{array}$ & Organic \\
\hline KY430522 & 20 & Microdochium & $\begin{array}{l}\text { Pathotroph- } \\
\text { Symbiotroph }\end{array}$ & Conventional \\
\hline KY430523 & 20 & Microdochium & $\begin{array}{l}\text { Pathotroph- } \\
\text { Symbiotroph }\end{array}$ & Conventional \\
\hline KY430524 & 20 & Microdochium & $\begin{array}{l}\text { Pathotroph- } \\
\text { Symbiotroph }\end{array}$ & Conventional \\
\hline KY430525 & 20 & Microdochium & $\begin{array}{l}\text { Pathotroph- } \\
\text { Symbiotroph }\end{array}$ & Conventional \\
\hline KY430526 & 20 & Microdochium & $\begin{array}{l}\text { Pathotroph- } \\
\text { Symbiotroph }\end{array}$ & Conventional \\
\hline KY430527 & 3 & Clavulina & Symbiotroph & Organic \\
\hline KY430528 & 7 & Ascomycota & - & Organic \\
\hline KY430529 & 7 & Ascomycota & - & Organic \\
\hline KY430530 & 10 & Leucosporidium & - & Organic \\
\hline KY430531 & 26 & Fusarium equiseti & $\begin{array}{l}\text { Pathotroph- } \\
\text { Saprotroph- } \\
\text { Symbiotroph }\end{array}$ & Conventional \\
\hline KY430532 & 32 & $\begin{array}{l}\text { Podospora } \\
\text { dimorpha }\end{array}$ & $\begin{array}{l}\text { Saprotroph- } \\
\text { Symbiotroph }\end{array}$ & Organic \\
\hline KY430533 & 26 & Fusarium equiseti & $\begin{array}{l}\text { Pathotroph- } \\
\text { Saprotroph- } \\
\text { Symbiotroph }\end{array}$ & Conventional \\
\hline KY430534 & 20 & Microdochium & $\begin{array}{l}\text { Pathotroph- } \\
\text { Symbiotroph }\end{array}$ & Conventional \\
\hline KY430536 & 8 & Cystofilobasidium & Saprotroph & Organic \\
\hline
\end{tabular}




\begin{tabular}{|c|c|c|c|c|}
\hline sequence ID & MOTU & species & trophic mode & farming system \\
\hline & & macerans & & \\
\hline KY430537 & 7 & Ascomycota & - & Organic \\
\hline KY430539 & 7 & Ascomycota & - & Conventional \\
\hline KY430540 & 22 & Microdochium & $\begin{array}{l}\text { Pathotroph- } \\
\text { Symbiotroph }\end{array}$ & Conventional \\
\hline KY430541 & 20 & Microdochium & $\begin{array}{l}\text { Pathotroph- } \\
\text { Symbiotroph }\end{array}$ & Conventional \\
\hline KY430542 & 7 & Ascomycota & - & Organic \\
\hline KY430543 & 7 & Ascomycota & - & Organic \\
\hline KY430544 & 7 & Ascomycota & - & Organic \\
\hline KY430545 & 7 & Ascomycota & - & Organic \\
\hline KY430546 & 7 & Ascomycota & - & Organic \\
\hline KY430547 & 20 & Microdochium & $\begin{array}{l}\text { Pathotroph- } \\
\text { Symbiotroph }\end{array}$ & Conventional \\
\hline KY430548 & 1 & $\begin{array}{l}\text { Malassezia } \\
\text { restricta }\end{array}$ & $\begin{array}{l}\text { Pathotroph- } \\
\text { Saprotroph }\end{array}$ & Conventional \\
\hline KY430549 & 20 & Microdochium & $\begin{array}{l}\text { Pathotroph- } \\
\text { Symbiotroph }\end{array}$ & Conventional \\
\hline KY430550 & 8 & $\begin{array}{l}\text { Cystofilobasidium } \\
\text { macerans }\end{array}$ & Saprotroph & Conventional \\
\hline KY430551 & 20 & Microdochium & $\begin{array}{l}\text { Pathotroph- } \\
\text { Symbiotroph }\end{array}$ & Conventional \\
\hline KY430552 & 25 & Ascomycota & - & Organic \\
\hline KY430553 & 2 & $\begin{array}{l}\text { Malassezia } \\
\text { restricta }\end{array}$ & $\begin{array}{l}\text { Pathotroph- } \\
\text { Saprotroph }\end{array}$ & Conventional \\
\hline KY430555 & 7 & Ascomycota & - & Organic \\
\hline KY430556 & 22 & Microdochium & $\begin{array}{l}\text { Pathotroph- } \\
\text { Symbiotroph }\end{array}$ & Conventional \\
\hline KY430557 & 22 & Microdochium & $\begin{array}{l}\text { Pathotroph- } \\
\text { Symbiotroph }\end{array}$ & Conventional \\
\hline KY430558 & 7 & Ascomycota & - & Conventional \\
\hline KY430559 & 7 & Ascomycota & - & Conventional \\
\hline KY430560 & 4 & Polyporales & - & Conventional \\
\hline KY430561 & 23 & Leotiomycetes & - & Conventional \\
\hline KY430563 & 20 & Microdochium & Pathotroph- & Conventional \\
\hline
\end{tabular}




\begin{tabular}{|c|c|c|c|c|}
\hline sequence ID & MOTU & species & trophic mode & farming system \\
\hline & & & Symbiotroph & \\
\hline KY430564 & 20 & Microdochium & $\begin{array}{l}\text { Pathotroph- } \\
\text { Symbiotroph }\end{array}$ & Conventional \\
\hline KY430565 & 7 & Ascomycota & - & Conventional \\
\hline KY430566 & 7 & Ascomycota & - & Conventional \\
\hline KY430567 & 7 & Ascomycota & - & Conventional \\
\hline KY430568 & 7 & Ascomycota & - & Conventional \\
\hline KY430569 & 24 & Leotiomycetes & - & Conventional \\
\hline KY430570 & 20 & Microdochium & $\begin{array}{l}\text { Pathotroph- } \\
\text { Symbiotroph }\end{array}$ & Conventional \\
\hline KY430571 & 37 & $\begin{array}{l}\text { Dioszegia } \\
\text { hungarica }\end{array}$ & $\begin{array}{l}\text { Pathotroph- } \\
\text { Saprotroph- } \\
\text { Symbiotroph }\end{array}$ & Conventional \\
\hline KY430572 & 20 & Microdochium & $\begin{array}{l}\text { Pathotroph- } \\
\text { Symbiotroph }\end{array}$ & Conventional \\
\hline KY430573 & 35 & $\begin{array}{l}\text { Vishniacozyma } \\
\text { victoriae }\end{array}$ & $\begin{array}{l}\text { Pathotroph- } \\
\text { Saprotroph- } \\
\text { Symbiotroph }\end{array}$ & Conventional \\
\hline KY430574 & 17 & Holtermanniella & - & Conventional \\
\hline KY430575 & 20 & Microdochium & $\begin{array}{l}\text { Pathotroph- } \\
\text { Symbiotroph }\end{array}$ & Conventional \\
\hline KY430576 & 20 & Microdochium & $\begin{array}{l}\text { Pathotroph- } \\
\text { Symbiotroph }\end{array}$ & Conventional \\
\hline KY430577 & 20 & Microdochium & $\begin{array}{l}\text { Pathotroph- } \\
\text { Symbiotroph }\end{array}$ & Conventional \\
\hline KY430578 & 24 & Leotiomycetes & - & Conventional \\
\hline KY430579 & 1 & Malassezia & $\begin{array}{l}\text { Pathotroph- } \\
\text { Saprotroph }\end{array}$ & Conventional \\
\hline KY430580 & 0 & Agaricomycetes & - & Conventional \\
\hline KY430581 & 18 & Fusarium nurragi & $\begin{array}{l}\text { Pathotroph- } \\
\text { Saprotroph- } \\
\text { Symbiotroph }\end{array}$ & Conventional \\
\hline KY430582 & 0 & Agaricomycetes & - & Conventional \\
\hline KY430583 & 0 & Agaricomycetes & - & Conventional \\
\hline KY430584 & 16 & $\begin{array}{l}\text { Paraphoma } \\
\text { radicina }\end{array}$ & $\begin{array}{l}\text { Pathotroph- } \\
\text { Saprotroph }\end{array}$ & Organic \\
\hline
\end{tabular}




\section{Table 2 (on next page)}

Phylogenetic diversity and structure of the belowground fungal communities associated with roots of winter wheat (Triticum aestivum) collected from in conventional and organic farming systems.

The observed mean nearest phylogenetic taxon distance (MNTD) and mean phylogenetic distance (MPD), as well as the mean and standard deviation of 9999 randomly generated communities, are given. The significance ( $p$-values) of the MNTD and MPD values of samples was calculated with the 'picante' package in R (Kembel et al. 2010) by comparing the values with those of random communities. 


\begin{tabular}{|c|c|c|c|c|c|c|c|c|c|}
\hline Farming system & ntaxa & mntd.obs & mntd.rand.mean & mntd.rand.sd & mntd.obs.rank & mntd.obs.z & mntd.obs.p & runs & \\
\hline Conventional & 19 & 0.65646923 & 0.58565766 & 0.0390507 & 9656 & 1.81332398 & 0.9656 & 9999 & dispersed \\
\hline \multirow[t]{2}{*}{ Organic } & 28 & 0.52514116 & 0.56577169 & 0.02433867 & 478 & -1.6693818 & 0.0478 & 9999 & clustered \\
\hline & ntaxa & mpd.obs & mpd.rand.mean & mpd.rand.sd & mpd.obs.rank & mpd.obs.z & mpd.obs.p & runs & \\
\hline Conventional & 19 & 0.82247012 & 0.80006999 & 0.02666562 & 7886 & 0.84003779 & 0.7886 & 9999 & \\
\hline Organic & 28 & 0.78209976 & 0.79920574 & 0.01630606 & 1539 & -1.0490569 & 0.1539 & 9999 & \\
\hline
\end{tabular}

